Sharif University of Technology
Scientia Iranica
SCIENTIA

\title{
A comparison between entropy generation analysis and first law efficiency in a monoplane Wells turbine
}

\author{
E. Lakzian*, R. Soltanmohamadi and M. Nazeryan \\ Department of Mechanical Engineering, Hakim Sabzevari University, Sabzevar, Iran.
}

Received 5 July 2015; received in revised form 27 October 2015; accepted 4 January 2016

\section{KEYWORDS}

Wave energy

conversion;

Fluid machinery;

Wells turbine;

Efficiency;

Entropy generation;

CFD.

\begin{abstract}
Wells turbine is a promising self-rectifying device in the field of ocean wave energy conversion. This study presents an Entropy Generation Analysis (EGA) of isothermal flow through a monoplane Wells turbine. The numerical computation has performed by solving the steady, incompressible, and three-dimensional ReynoldsAveraged Navier-Stokes (RANS) equations with RNG $k-\varepsilon$ turbulence model in a noninertial reference frame rotating with the turbine rotor. Then, local entropy generation rates, related to viscous dissipation around rotor blades, were calculated from the velocity fields. The results indicate that separation and boundary-layer interaction have a direct effect on the entropy generation. The blade entropy generation decreases from hub to tip and from leading edge to trailing edge in suction surface. Also, the result of comparison shows that the point of minimum entropy generation coincides with the point of maximum first law efficiency of thermodynamics. The results prove that viscous entropy generation distribution provides designers with useful information about the causes of flow irreversibilities. Future monoplane Wells turbine designs should concentrate essentially on optimizing the blade geometry.
\end{abstract}

(C) 2016 Sharif University of Technology. All rights reserved.

\section{Introduction}

Among the different types of renewable energy, ocean wave has attracted attention of researchers in the recent past because of its perennial availability, minimum health hazards, and high energy density [1]. Recent evaluations have indicated that the wave energy in Egypt [2], Italy [3], and Turkey [4] is possible for wave energy conversion. Zabihian et al. [5] investigated the energy potentials of these resources in Iran and the possibility of exploiting them; they concluded that Iran has a high potential to exploit ocean renewable energies. In the past two decades, several types of Wave Energy Converters (WEC) and related technologies have been investigated [6]. Among these energy converters, a wide range of research activities are devoted

\footnotetext{
*. Corresponding author.

E-mail address: e.lakzian@hsu.ac.ir (E. Lakzian)
}

to the Oscillating Water Column (OWC) systems which perform the conversion of the wave motion into a reciprocating (bi-directional) airflow through a turbine [7]. In the initial stages of advancement, conventional turbines were used within OWC systems. But, these turbines needed flow-rectifying valves and guide vanes. Wells turbine, a concept proposed by Wells in 1976, eliminated the need for flow-rectifying valves and guide vanes [8]. Wells turbine is known as one of the most important parts of the OWC and is the simplest self-rectifying air turbine with a symmetrical aerofoil (usually belonging to the NACA00XX series) blades with respect to a normal plane to the rotational axis, and it is not sensitive to the direction of incoming flow. Figure 1 presents schematic of monoplane Wells turbine as follows.

This axial-flow turbine is employed by OWC wave energy devices due to its technical simplicity, reliability, high rotational velocity, and design robustness [9]. 


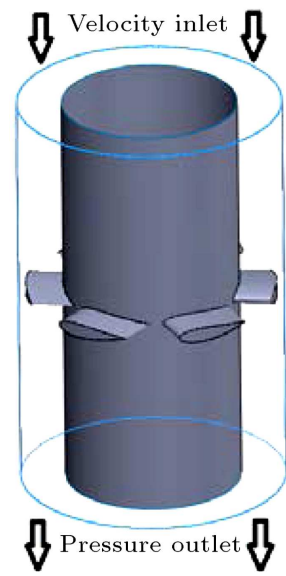

Figure 1. Schematic of Wells turbine.

While it carries solid advantages, the Wells turbine has intrinsic drawbacks in comparison with conventional turbines, and they are as follows: lower efficiency, poorer starting, higher noise level, short operating range, higher axial force, as well as lower tangential force. So, many scholars have tried to recognize the optimum conditions to overcome such drawbacks and improve the performance of Wells turbines [10,11]. There are several articles which describe the performance of the Wells turbine with focus on the overall operational characteristics [12-14]. Takao et al. [15] investigated the Wells turbines with variable thickness blades experimentally. They indicated that the stall characteristic depends on the blade profile at tip, and the stall characteristics are improved by increasing blade thickness at the blade tip.

With recent developments in computer hardware and software, it has now become practicable to conduct a reasonable computation of $3-\mathrm{D}$ turbulent flow fields through complex geometries, such as those found in the Wells turbine. Watterson et al. [16,17] studied the effects of solidity and tip clearance on the performance of a Wells turbine, torque, and efficiency. Numerical analysis of the influence of the turbine blade without tip clearance on the turbine performance has been performed by Thakker et al. [18]. Torresi et al. [19] studied a variable cord Wells turbine by the actuator disk theory and CFD simulation. They showed that for low values of flow coefficient, the proposed configuration has a higher torque coefficient in comparison with the constant chord blade. Mohamed and Shaaban [20] numerically investigated the standard NACA 0021 and a proposed airfoil with optimized profile. They found that self-pitch control of Wells turbines can improve the turbine efficiency and delay the turbine starting point simultaneously. Starzmann and Carolus [21] investigated the effect of cascade solidity and the hubto-tip ratio on the aeroacoustic performance of Wells turbine rotors numerically and experimentally. This research showed that the high hub-to-tip ratio and high solidity design increase the maximum range of operation without stall. Also, in this investigation, it was found that steady-state RANS approach cannot predict the onset of stall due to the inherent unsteadiness of the flow in this regime.

As mentioned above, analyses of the airflow through the Wells turbine have been carried out over the years by means of experimental and numerical methods to improve its performance. However, such studies employ the first law of thermodynamics, and the process irreversibilities are not represented in the analysis.

On the other hand, the second law of thermodynamics analysis should be considered to evaluate the sources of irreversibilities (entropy generation) related to heat transfer, friction, and other non-idealities within systems. A number of studies were performed on the second law analysis and the entropy generation in different kinds of turbines, such as gas turbines [22], wet steam flow turbines [23-25], and wind turbine [26]. For a real system, there is a direct proportionality between the entropy generation of the process and the amount of useful energy dissipated in the process [27]. Lower levels of entropy generation yield more efficient designs of energy systems. Therefore, in recent years, a topic of great attention in the thermo-fluid area is the entropy minimization. Bejan [27] studied the different sources of irreversibility in applied thermal engineering as a reason for destroying the exergy of a system. Therefore, it makes good sense to concentrate on the irreversibility of heat transfer and fluid flow processes. Bejan $[28,29]$ indicated that entropy generation in convective fluid flow is due to thermal and viscous dissipations.

A small number of studies have been dedicated to the investigation of the EGA in Wells turbine. For example, Shaaban [30] investigated an exergy analysis of steady 3D incompressible flow through a biplane Wells turbine with stagger angle of 45-deg between rotors. He indicated that efficiency can be significantly improved by improving the downstream rotor performance, optimizing the blade profile in the zone extending from leading edge to the position of maximum thickness and reducing interaction between rotor and boundary layers, especially at the rotor tip. Shehata et al. [31] analyzed entropy generation due to viscous dissipation around different airfoils under 2D steady flow condition. They found that the entropy generation around the NACA0015 airfoil blade is less than the entropy generation around NACA0012, NACA0020, and NACA0021 airfoils.

The major goal of this paper is to investigate critical zones of the blade geometry based on EGA on a monoplane Wells turbine. Firstly, a numerical computation has been performed by solving the steady, incompressible, and three-dimensional 
Reynolds-averaged Navier-Stokes equations with RNG $k-\varepsilon$ turbulence model in a non-inertial reference frame rotating with the rotor. In the next step, the numerical model is validated by comparing the computed parameters with the available experimental data [32]. Then, the aerodynamic characteristics and comparison between first law efficiency and entropy generation are investigated. In this paper, good understanding of the energy conversion process, EGA and sources of irreversibility inside monoplane Wells turbine, and recommendations for future design optimization are presented.

\section{Force analysis of Wells turbine}

The airflow through the Wells turbine generates a lift force $\left(F_{L}\right)$ normal to the relative velocity $(W)$ and a drag force $\left(F_{D}\right)$ in the direction of relative velocity. These lift and drag forces are resolved into the axial force $\left(F_{A}\right)$ and the tangential force $\left(F_{T}\right)$, where direction of $F_{T}$ is independent of the axial flow direction, as shown in Figure 2.

$$
\begin{aligned}
& F_{T}=F_{L} \sin \alpha-F_{D} \cos \alpha, \\
& F_{A}=F_{L} \cos \alpha-F_{D} \sin \alpha .
\end{aligned}
$$

According to Figure 2, the flow angle of attack changes its sign depending on the air-flow direction. Tangential force on the rotor works only in the same direction for both positive and negative values of angle of attack $( \pm \alpha)$. The force $F_{T}$ is responsible for the torque, and consequently for the blade power, while the axial force $F_{A}$ yields an axial thrust along the axis of the rotor, which has to be absorbed by the bearings.

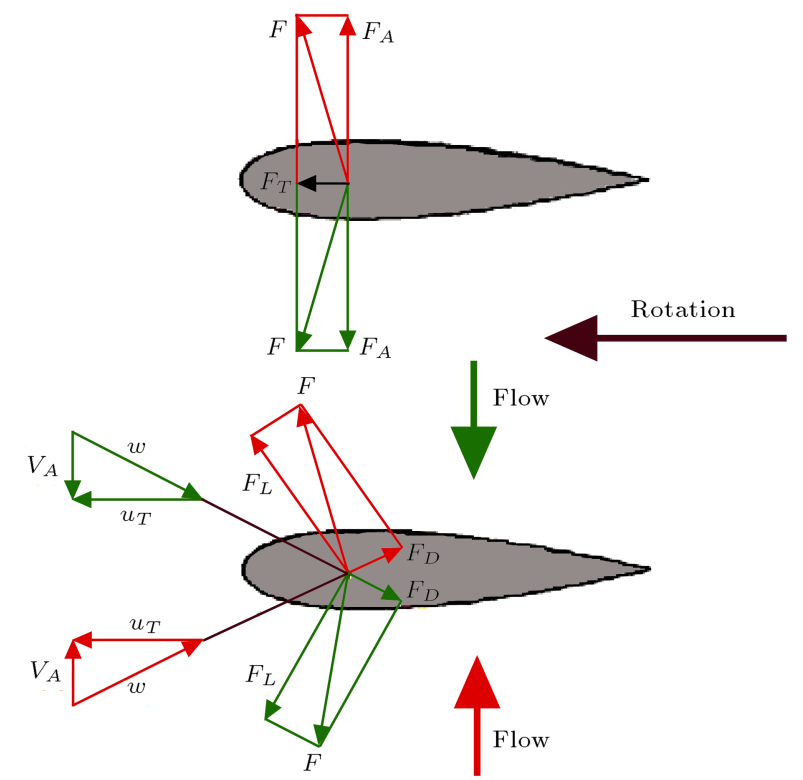

Figure 2. Velocity diagram and forces acting on a Wells turbine blade.

\section{Numerical method and calculation}

For such a case, steady-state computations are appropriate because the air flow frequency in the OWC wave energy converter is so small $(f<1 \mathrm{~Hz})$ that dynamic effects are negligible [33]. Moreover, compressibility effect is neglected because of the low Mach number flow [34]. A finite volume approach was used to discretize the three-dimensional ReynoldsAveraged Navier-Stokes (RANS) equations. Also, the pressure-velocity coupling is calculated using the SIMPLE algorithm. The convective terms are discretized using a second-order-accurate upwind scheme, whereas pressure and viscous terms are discretized by means of a second-order-accurate centered scheme. An implicit solver is employed for simulation. Turbulence is modeled with a RNG $k-\varepsilon$ model in order to properly predict the behavior of turbulent swirling flow. And, tip clearance region is considered to obtain an accurate prediction of the turbine performance.

The computation was carried out by changing the rotational speed of the rotor from high speed to low speed under a constant axial velocity. Deep stall condition is avoided in this research because efficiency and power rapidly decrease in this condition. And, because of an extremely small output power, there is no practical interest in the operating range below 6 degrees [35-38]. So, in this paper, a typical operating range is considered: an angle of attack $\alpha$ varying between 6 and 14 degrees, or equivalently, a flow coefficient $\varphi$ varying between 0.105 and 0.249 . The geometric data of the turbine are summarized below in Table 1.

Due to the circumferential symmetry, only one sixth of the annulus (Figure 3 ) has been computed, imposing periodic boundary conditions on the tangential direction. According to Figure 3, the computational domain has been restricted in the axial direction to six chord lengths upstream and ten chord lengths downstream of the blade in order to provide fully unrestricted flow around the aerofoil section [39]. A uniform velocity profile of the airflow has been specified at inlet and inflow values of turbulent intensity equal

Table 1. Specification of Wells turbine geometry.

\begin{tabular}{lc} 
Number of blades $(\boldsymbol{N})$ & 6 \\
Blade profile & NACA0020 \\
Chord length $(\boldsymbol{L})$ & $0.090 \mathrm{~m}$ \\
Solidity at mean radius $\left(\boldsymbol{\sigma}_{\boldsymbol{R}}\right)$ & 0.67 \\
Aspect Ratio $(\mathbf{A R})$ & 0.5 \\
Hub-to-tip ratio $(\boldsymbol{\nu})$ & 0.7 \\
Tip diameter $\left(\boldsymbol{D}_{\boldsymbol{t}}\right)$ & $0.298 \mathrm{~m}$ \\
Tip Clearance $(\mathrm{TC})$ & $0.001 \mathrm{~m}$ \\
Blade sweep ratio $(\mathbf{f})$ & 0.35 \\
\hline
\end{tabular}




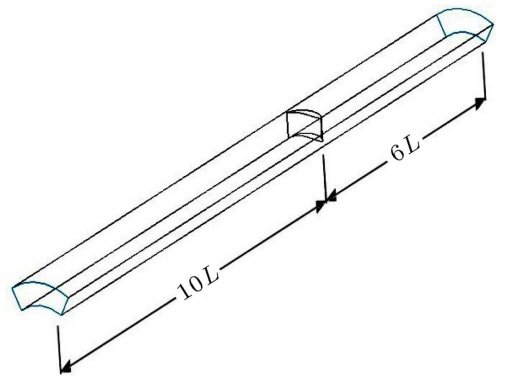

Figure 3. Numerical domain ( $L$ : blade cord length).

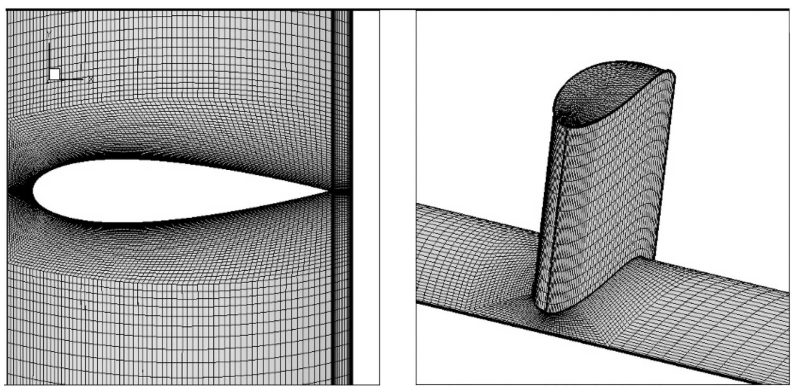

Figure 4. Computational grid: discretization of the blade and hub surfaces.

to $1 \%$ and turbulence length scale equal to $1 / 100$ chord length. Reynolds number is based on the blade chord length and relative velocity at mean radius, which is about $3.6 \times 10^{5}$. In addition, value of inlet axial velocity is equal to $8.9 \mathrm{~m} / \mathrm{s}$. In this research, the standard wall function was used, so that the blade adjacent cells required the $Y^{+}$value in the range of 3060 . Therefore, the $Y^{+}$value was generally around 55 . No-slip boundary conditions are imposed on the blade surfaces, hub, and casing. Radial equilibrium static pressure distribution has been applied to the outlet boundary of the annulus.

A global view of the meshes on the blade and hub surfaces is shown in Figure 4. Computational domain is divided into three domains in order to obtain the structure mesh (four volumes in inlet domain and outlet domain, and thirteen volumes in middle domain [40,41]). Elements of the mesh are gradually reduced in size towards the middle domain. Ten nonuniformly spaced cells are used in the radial tip clearance zone. The mesh generation has been carried out by means of a fully structured multi-block grid, using quasi-orthogonal cells along the blade surfaces and $\mathrm{H}-$ type mesh elsewhere, except in the tip clearance region with an unstructured mesh, as shown in Figure 4.

\section{Numerical results and discussions}

\subsection{Investigated non-dimensional parameters}

The turbine performance is described by turbine efficiency, $\eta$, torque coefficient, $C_{T}$, and input coefficient, $C_{A}$, against flow coefficient, $\phi$. Also, in this paper, the validation and accuracy of computation are investigated by the above non-dimensional parameters in the later section. The definitions of these non-dimensional parameters are as follows:

$$
\begin{aligned}
& \phi=\frac{V_{A}}{u_{T}}=\tan \alpha, \\
& \eta=\frac{T_{0} \omega}{\Delta P Q}=\frac{C_{T}}{C_{A} \phi}, \\
& C_{T}=\frac{T_{0}}{\frac{\rho\left(V_{A}^{2}+u_{T}^{2}\right) A r}{2}}, \\
& C_{A}=\frac{\Delta P}{\frac{\rho\left(V_{A}^{2}+u_{T}^{2}\right)}{2}},
\end{aligned}
$$

where $u_{T}=\omega r$ indicates rotational speed at the mean radius of rotor $(r), \omega$ is the rotor angular velocity, $V_{A}$ is the inlet axial flow velocity, and $Q$ is the volume flow-rate. $T$ and $\Delta P$ denote the turbine's shaft torque and total pressure drop across the turbine, respectively. Values of the flow coefficient from $\phi=0.105$ up to $\phi=$ 0.249 were obtained by varying the turbine rotational speed, while keeping the axial velocity constant.

\subsection{Grid independence}

In the first step, the grid independence tests were carried out to ensure minimum influence of grid size on the CFD results. Three different $3 \mathrm{D}$ grids composed of 121164,238876 , and 498366 cells on CFD model are tested. The two coarsest grids are associated with a large variation of the turbine efficiency. The finer remaining grid employing 498366 cells leads to a variation of the turbine efficiency less than $0.53 \%$. Finally, since the cost of the CFD evaluation obviously increases rapidly with the number of grid cells, only the results obtained from intermediate grids are used in the present research.

\subsection{CFD model validation}

In the second step, the published experimental results of Takao et al. [32] are used in order to validate the present computational results. Figure 5 shows the quite good agreement between numerical and experimental results in terms of three expressed non-dimensional parameters.

\subsection{Turbine aerodynamics}

Figure 6 shows the local pressure coefficient distribution on the suction and pressure surfaces of the blade in three planes (near hub, mid span, and near tip) for three values of $\varphi$ that indicates an acceptable qualitative trend. According to Figure 6, from hub toward tip, the confined area of $C_{p}$ plot, and hence lift force acting on the blade increase, especially in near leading edge portion. 


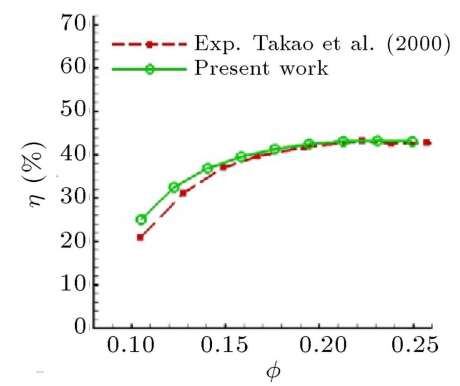

(a)

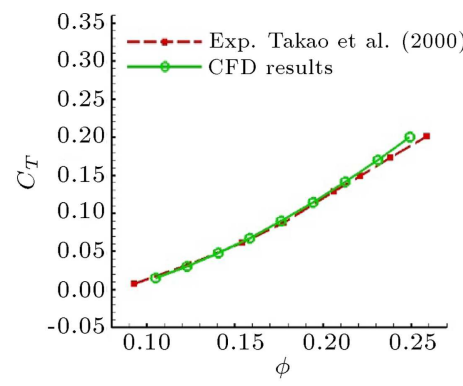

(b)

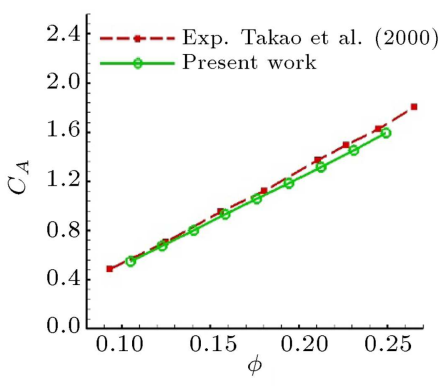

(c)

Figure 5. Comparison of calculated parameters with experimental result [32]: (a) Efficiency; (b) torque coefficient; and (c) input coefficient.

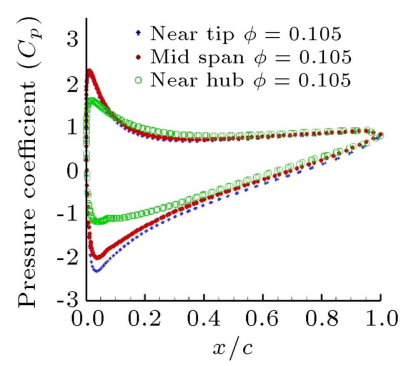

(a)

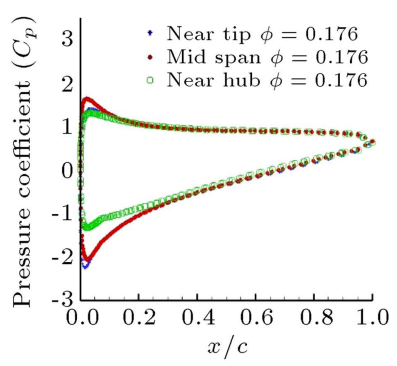

(b)

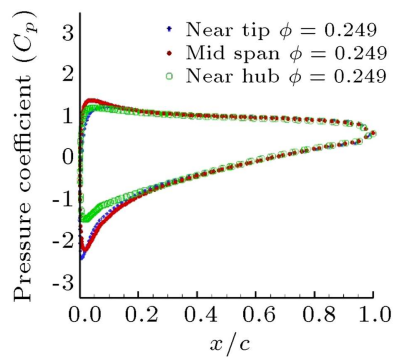

(c)

Figure 6. Pressure coefficient distribution at near hub, mid span, and near tip plane for different flow coefficients, $\phi$.

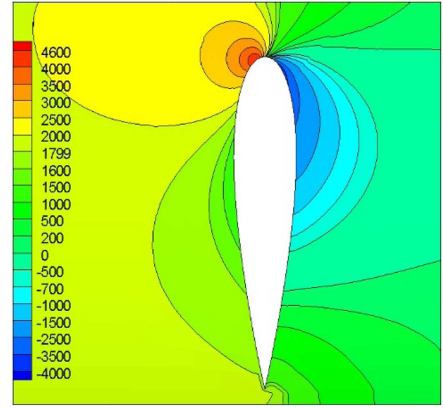

(a)

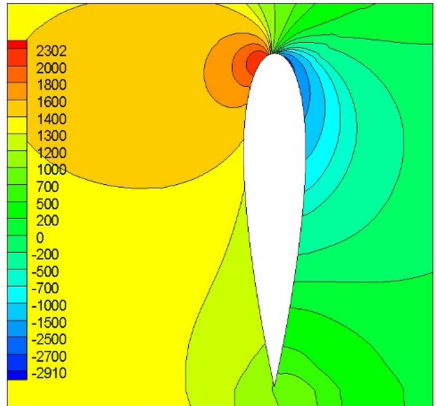

(b)

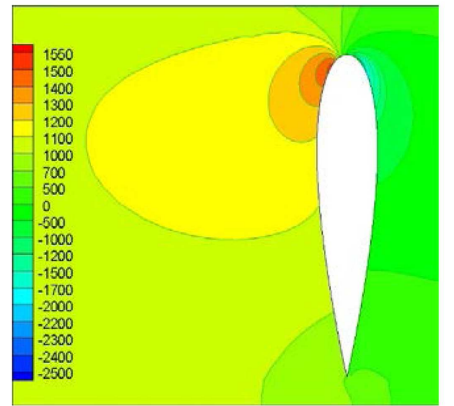

(c)

Figure 7. Static pressure distribution $(\mathrm{Pa})$ at mid-span plane for different flow coefficients: (a) $\phi=0.105 ;(\mathrm{b}) \phi=0.176$; and (c) $\phi=0.249$.

Static pressure distribution on mid-span plane of the turbine blade has been shown in Figure 7 in order to find out the stagnation point and performance on the blade profile for three flow coefficients; $\phi=0.105$, 0.176 (before stall), and $\phi=0.249$ (near stall). The axial flow is from left to right in Figure 7 . A region of high pressure begins to extend near leading edge of the pressure surface at flow coefficient of $\phi=0.105$. As shown in Figure 7(a), stagnation point is very close to leading edge of the turbine blade at this flow coefficient. As the flow coefficient increases, it moves towards midportion of the blade from leading edge (Figure $7(\mathrm{a})$ (c)). It seems that the high-pressure region at $\phi=$ 0.249 is exceeding the position of maximum thickness of blade, and hence causes the turbine to be about to start stall.

According to the static pressure distribution on mid-span plane near trailing edge of the suction surface of the blade, it can be clearly observed that the airflow enters through the trailing edge to mid-portion. Figure 7 also shows that the highest momentum change, and hence energy conversion occurs near to the leading edge of the rotor blades on the suction side.

\subsection{Entropy generation analysis}

EGA is performed to investigate the effect of irreversibility factors in order to further explain the energy conversion process of monoplane Wells turbine. In this paper, these factors could be due to deflection of velocity vectors at leading edge, boundary layer separation, interaction between boundary layers of casing and the blade tip, and interaction between boundary layers of the hub and the blades. The wake and boundary layer interaction substantially affect the 
torque produced by the blade at low values of the flow coefficient because of decreasing flow angle of attack. All of these factors cause entropy generation.

In the absence of phase changes and chemical reactions, local entropy generation rate equation for incompressible Newtonian fluid can be given as [29]:

$$
S_{\text {gen }}^{\prime \prime \prime}=\frac{K}{T^{2}}(\nabla T)^{2}+\frac{\mu}{T} \varphi \succ 0 .
$$

Here, $S_{\text {gen }}^{\prime \prime \prime}$ is volumetric entropy generation rate that is computed per unit volume $\left(\mathrm{W} / \mathrm{m}^{3} \mathrm{~K}\right) . K, T, \mu$, and $\varepsilon$ are thermal conductivity, local absolute temperature, viscosity, and viscous dissipation function, respectively. As seen in Eq. (7), the entropy generation rate and irreversibility are divided into its thermal and viscous part. First part represents the entropy generation due to finite temperature difference, but the second one represents the entropy generation due to viscous effects (fluid friction). For isothermal flow in a Wells turbine, main contribution of entropy generation is due to the viscous part, while the thermal part is almost negligible.

In Cartesian notation, viscous dissipation function is expressed in three-dimensional coordinates as follows:

$$
\begin{aligned}
\varphi=2 & {\left[\left(\frac{\partial u}{\partial x}\right)^{2}+\left(\frac{\partial V}{\partial y}\right)^{2}+\left(\frac{\partial w}{\partial z}\right)^{2}\right]+\left(\frac{\partial u}{\partial y}+\frac{\partial V}{\partial x}\right)^{2} } \\
& +\left(\frac{\partial u}{\partial z}+\frac{\partial w}{\partial x}\right)^{2}+\left(\frac{\partial V}{\partial z}+\frac{\partial w}{\partial y}\right)^{2}
\end{aligned}
$$

where $u, v$, and $w$ are local velocity components in $x, y$, and $z$ directions, respectively. According to the above formula, it is understood that the local entropy generation rates are computed directly from local velocities. In fact, high values of velocity gradients cause high values of entropy generation.

Therefore, the total entropy generation rate over the volume can be computed as follows:

$$
S_{\text {gen }}=\iiint\left(\frac{\mu}{T} \varphi\right) d x d y d z
$$

Eq. (9) is employed to compute the total entropy generation rate throughout computational domain (one blade) for modeled Wells turbine.

According to Figure 8, there is a negative correlation between the first law efficiency of thermodynamics and entropy generation; the minimum entropy generation coincides with the maximum first law efficiency of thermodynamics at flow coefficient equal to 0.231 . For this reason, flow coefficient of 0.231 is considered as the turbine design point. As shown in Figure 8, the efficiency considerably increases with increasing the flow coefficient up to the design point because of the

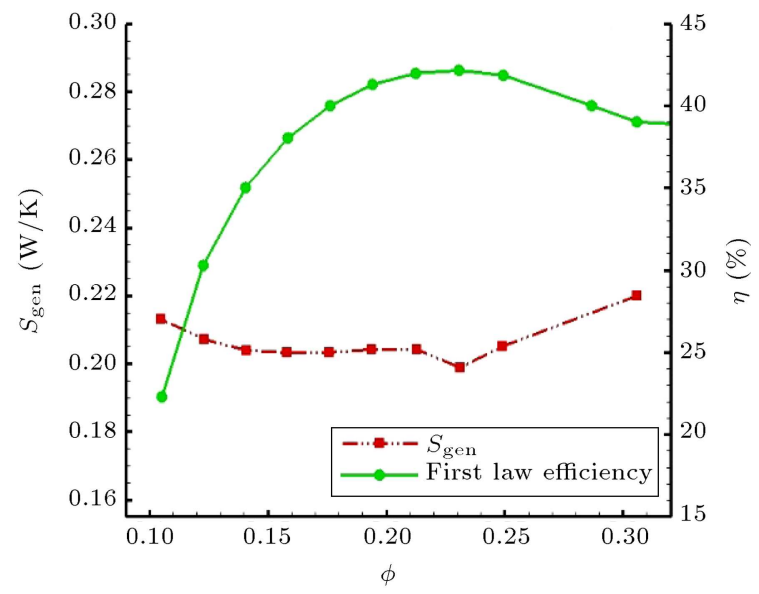

Figure 8. Comparison of first law efficiency with entropy generation.

rapid increase of rotor torque. Then, the turbine will start to stall when the flow coefficient exceeds 0.249 . As the value of $\varphi$ decreases from 0.16 to 0.105 , there is a marked increase in the value of entropy generation and the sharp decrease in the value of first law efficiency, and this could be due to the high level of interaction between the wake of upstream blade and the boundary layer on the suction surface of the blade.

Local viscous entropy generation of turbine blade at design flow coefficient $\phi=0.231$ is shown in Figure 9. According to this figure, entropy generation decreases from leading edge to trailing edge. Also, the highest entropy generation and momentum change also occur at the zone extending from blade leading edge to the position of maximum blade thickness on the suction side, which emphasizes the importance of irreversibilities and losses at this zone. High values of entropy generation are occurred near the blade hub because of interaction between boundary layers of the hub and the blade and deep flow separation on the suction side of the blade. Moreover, high entropy generation rate near the blade tip is due to boundary layers' interaction between casing and blade

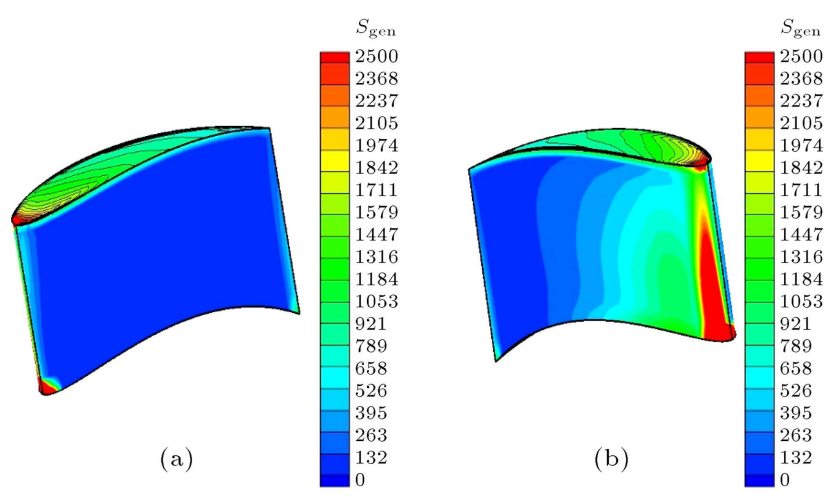

Figure 9. Local viscous entropy generation distribution on sides and tip of the blade: (a) Pressure side and, (b) suction side, for $\phi=0.231$. 
tip. Hence, size of tip clearance passage region has the high influence on the Wells turbine performance.

Low entropy generation zone is observed on the pressure side of the blades, because there is lower velocity gradient than the suction surface. As a result, performance of monoplane Wells turbine can be considerably improved by optimizing the blade profile (geometric optimization) in high entropy generation zones and decreasing interaction between rotor and boundary layers at the blade hub and tip.

\section{Conclusions}

In this paper, entropy generation analysis for a constant chord Wells turbine was studied numerically. This analysis was carried out by solving the three dimensional Reynolds-averaged Navier-Stokes equations with RNG $k-\varepsilon$ turbulence model. A good agreement between the experimental and computational results was achieved using a structured mesh consisting of 238876 cells. According to the obtained results, the minimum entropy generation is coincided with the maximum first law efficiency of thermodynamics at flow coefficient equal to 0.231 .

The computational results concentrate on the very important issues in the monoplane Wells turbine which are the separation and boundary layer interaction. The present CFD analysis shows significant influence of these issues on turbine performance.

Also, the results show that the highest entropy generation and momentum change occur at the zone extending from blade leading edge to the position of maximum blade thickness on the suction side. So, optimization of blade geometry in this zone can yield considerable improvement in the Wells turbine performance, especially near the stall point. Future research will be directed towards improving the tip clearance region and optimizing the blade geometry in order to enhance monoplane Wells turbine performance.

\section{Nomenclature}

$\begin{array}{ll}A & A=\pi D_{t}^{2}\left(1-\nu^{2}\right) / 4\left(\mathrm{~m}^{2}\right) \\ \text { AR } & \text { Aspect Ratio } H / l(-) \\ D & \text { Diameter }(\mathrm{m}) \\ f & \text { Blade sweep ratio }(-) \\ F_{A} & \text { Axial force }(\mathrm{N}) \\ F_{T} & \text { Tangential force }(\mathrm{N}) \\ F_{L} & \text { Lift force }(\mathrm{N}) \\ F_{D} & \text { Drag force }(\mathrm{N}) \\ k & \text { Thermal conductivity (Watt } / \mathrm{m} . \mathrm{K}) \\ l & \text { Blade cord length }(\mathrm{m}) \\ N & \text { Number of blade }\end{array}$

$\begin{array}{ll}Q & \text { Volume flow rate }\left(\mathrm{m}^{3} / \mathrm{s}\right) \\ R & \text { Radius }(\mathrm{m}) \\ r & \text { Mean radius }(\mathrm{m}) \\ S_{\text {gen }}^{\prime \prime \prime} & \text { Total volumetric entropy generation } \\ & \text { rate }\left(\text { Watt } / \mathrm{m}^{3} . \mathrm{K}\right) \\ T_{0} & \text { Torque }(\mathrm{N} . \mathrm{m}) \\ V_{A} & \text { Axial velocity }(\mathrm{m} / \mathrm{s}) \\ u_{T} & \text { Circumferential velocity }(\mathrm{m} / \mathrm{s}) \\ u & \text { Velocity in the } X \text { direction }(\mathrm{m} / \mathrm{s}) \\ V & \text { Velocity in the } Y \text { direction }(\mathrm{m} / \mathrm{s}) \\ w & \text { Velocity in the } Z \text { direction }(\mathrm{m} / \mathrm{s}) \\ W & \text { Relative velocity }(\mathrm{m} / \mathrm{s}) \\ H & \text { Blade height }(\mathrm{m})\end{array}$

\section{Greek symbols}

$\begin{array}{ll}\alpha & \text { Angle of attack }\left({ }^{\circ}\right) \\ \nu & \text { Hub-to-tip ratio (-) } \\ \sigma & \text { Solidity at } r(-) \\ \phi & \text { Flow coefficient }(-) \\ \omega & \text { Angular velocity ( rad } / \mathrm{s}) \\ \eta & \text { Efficiency (-) } \\ \Delta p & \text { Total pressure drop across the blade } \\ \mu & \text { (Pa) } \\ \varphi & \text { Viscosity (Pa.s) } \\ \rho & \text { Viscous dissipation function }\left(1 / \mathrm{s}^{2}\right) \\ \text { Subscripts } & \left.\text { Air density (kg/m }{ }^{3}\right) \\ h & \text { hub } \\ t & \text { tip }\end{array}$

\section{References}

1. McCormick, M.E. and Kim, Y.C. "Utilization of ocean waves-wave to energy conversion", Proceedings of the International Symposium: Scripps Institute [sic] of Oceanography, La Jolla, California, U.S.A., June 1617: The Society (1987).

2. Bayoumi, A., Incecik, A., El Gamal, H. and Shalash, K. "Wave powered water desalination in Egypt", In Fourteenth International Water Technology Conference (IWTC), Cairo, Egypt (2010).

3. Vicinanza, D., Cappietti, L. and Contestabile, P. "Assessment of wave energy around Italy", in Proc. of the 8th European Wave and Tidal Energy Conference (2009).

4. Sağlam, M., Sulukan, E. and Uyar, T.S. "Wave energy and technical potential of Turkey", Journal of Naval Science and Engineering, 6(2), pp. 34-50 (2010). 
5. Zabihian, F. and Fung, A.S. "Review of marine renewable energies: Case study of Iran", Renewable and Sustainable Energy Reviews, 15(5), pp. 2461$2474(2011)$.

6. Clément, A., McCullen, P., Falcão, A., Fiorentino, A., Gardner, F., Hammarlund, K. and Thorpe, T. "Wave energy in Europe: current status and perspectives", Renewable and Sustainable Energy Reviews, 6(5), pp. 405-431 (2002).

7. Raghunathan, S., Setoguchi, T. and Kaneko, K. "The effect of inlet conditions on the performance of Wells turbine", Journal of Energy Resources Technology, 111(1), pp. 37-42 (1989).

8. Dhanasekaran, T. and Govardhan, M. "Computational analysis of performance and flow investigation on Wells turbine for wave energy conversion", Renewable Energy, 30(14), pp. 2129-2147 (2005).

9. Starzmann, R. and Carolus, T. "Effect of blade skew strategies on the operating range and aeroacoustic performance of the Wells turbine", Journal of Turbomachinery, 136(1), pp. 011003 (2014).

10. Brito-Melo, A., Gato, L. and Sarmento, A. "Analysis of Wells turbine design parameters by numerical simulation of the OWC performance", Ocean Engineering, 29(12), pp. 1463-1477 (2002).

11. Takao, M., Thakker, A., Abdulhadi, R. and Setoguchi, T. "Effect of blade profile on the performance of largescale Wells turbine", In The Fourteenth International Offshore and Polar Engineering Conference, International Society of Offshore and Polar Engineers (2004).

12. Gato, L.M.C. and Falcão, A.D.O. "Aerodynamics of the Wells turbine", International Journal of Mechanical Sciences, 30(6), pp. 383-395 (1988).

13. Inoue, M., Kaneko, K. and Setoguchi, T. "Determination of optimum geometry of Wells turbine rotor for wave energy generator. Part 2", In Energy Sources and Tech. Conf., New Orleans, USA (1986).

14. Setoguchi, T., Takao, M. and Kaneko, K. "A comparison of performances of turbines for wave power conversion", International Journal of Rotating Machinery, 6(2), pp. 129-134 (2000).

15. Takao, M., Takasaki, K., Okuhara, S. and Setoguchi, T. "Wells turbine for wave energy conversionimprovement of stall characteristics by the use of 3dimensional blades", Journal of Fluid Science and Technology, 9(3), JFST0052-JFST0052 (2014).

16. Watterson, J. and Raghunathan, S. "Computed effects of tip clearance on Wells turbine performance", in 35th Aerospace Sciences Meeting \& Exhibit, AIAA (1997).

17. Watterson, J. and Raghunathan, S. "Computed effects of solidity on Wells turbine performance", JSME International Journal Series B, 41(1), pp. 177-183(1998).

18. Thakker, A., Frawley, P., Daly, J. and Bajeet, E.S. "Preliminary 3D computational fluids dynamics analysis of the Wells turbine", In The Tenth International
Offshore and Polar Engineering Conference, International Society of Offshore and Polar Engineers (2000).

19. Torresi, M., Pranzo, D., Camporeale, S.M. and Pascazio, G. "Improved design of high solidity Wells turbine", in 9th European Wave and Tidal Energy Conference, Southampton, England (2011).

20. Mohamed, M. and Shaaban, S. "Optimization of blade pitch angle of an axial turbine used for wave energy conversion", Energy, 56, pp. 229-239 (2013).

21. Starzmann, R. and Carolus, T. "Model-based selection of full-scale Wells turbines for ocean wave energy conversion and prediction of their aerodynamic and acoustic performances", Proceedings of the Institution of Mechanical Engineers, Part A: Journal of Power and Energy, 0957650913503153 (2013).

22. Haseli, Y., Dincer, I. and Naterer, G. "Thermodynamic modeling of a gas turbine cycle combined with a solid oxide fuel cell", International Journal of Hydrogen Energy, 33(20), pp. 5811-5822 (2008).

23. Lakzian, E. and Masjedi, A. "Slip effects on the exergy loss due to irreversible heat transfer in a condensing flow", International Journal of Exergy, 14(1), pp. 2237 (2014).

24. Lakzian, E. and Shabani, S. "Analytical investigation of coalescence effects on the exergy loss in a spontaneously condensing wet-steam flow", International Journal of Exergy, 16(4), pp. 383-403 (2015).

25. Mahpeykar, M., Lakzian, E. and Amirirad, E. "Reduction of thermodynamic losses in a supersonic nucleating steam nozzle by spraying water droplets", Scientia Iranica, 16(3), pp. 253-262 (2009).

26. Pope, K., Dincer, I. and Naterer, G. "Energy and exergy efficiency comparison of horizontal and vertical axis wind turbines", Renewable Energy, 35(9), pp. 2102-2113 (2010).

27. Bejan, A., Entropy Generation Minimization: The Method of Thermodynamic Optimization of FiniteSize Systems and Finite-Time Processes, CRC Press (1995).

28. Bejan, A. "A study of entropy generation in fundamental convective heat transfer", Journal of Heat Transfer, 101(4), pp. 718-725 (1979).

29. Bejan, A. "The thermodynamic design of heat and mass transfer processes and devices", International Journal of Heat and Fluid Flow, 8(4), pp. 258-276 (1987).

30. Shaaban, S. "Insight analysis of biplane Wells turbine performance", Energy Conversion and Management, 59, pp. 50-57 (2012).

31. Shehata, A.S., Saqr, K.M., Shehadeh, M., Xiao, Q. and Day, A.H. "Entropy generation due to viscous dissipation around a Wells turbine blade: A Preliminary numerical study", Energy Procedia, 50, pp. 808-816 (2014).

32. Takao, M., Setoguchi, T., Kim, T.H., Kaneko, K. and Inoue, M. "The performance of Wells turbine with 3D 
guide vanes", in The Tenth International Offshore and Polar Engineering Conference, International Society of Offshore and Polar Engineers (2000).

33. Raghunathan, S. and Beattie, W. "Aerodynamic performance of contra-rotating Wells turbine for wave energy conversion", Proceedings of the Institution of Mechanical Engineers, Part A: Journal of Power and Energy, 210(6), pp. 431-447 (1996).

34. Raghunathan, S. "The Wells air turbine for wave energy conversion", Progress in Aerospace Sciences, 31(4), pp. 335-386 (1995).

35. Setoguchi, T. and Kaneko, K. "Aerodynamics of monoplane Wells turbine-A review", International Journal of Offshore and Polar Engineering, 4(1), pp. 68-75 (1994).

36. Setoguchi, T., Santhakumar, S., Takao, M., Kim, T.H. and Kaneko, K. "A modified Wells turbine for wave energy conversion", Renewable Energy, 28(1), pp. 7991 (2003).

37. Setoguchi, T. and Takao, M. "Current status of self rectifying air turbines for wave energy conversion", Energy Conversion and Management, 47(15), pp. 23822396 (2006).

38. Mohamed, M.H., Janiga, G., Pap, E. and Thévenin, D. "Multi-objective optimization of the airfoil shape of Wells turbine used for wave energy conversion", Energy, 36(1), pp. 438-446 (2011).

39. Gareev, A. "Analysis of variable pitch air turbines for oscillating water column (OWC) wave energy converters", PhD Thesis, School of Mechanical, Materials and Mechatronic Engineering, University of Wollongong (2011).

40. Torresi, M., Camporeale, S. and Pascazio, G. "Detailed CFD analysis of the steady flow in a Wells turbine under incipient and deep stall conditions", Journal of Fluids Engineering, 131(7), p. 071103 (2009).

41. Torresi, M., Camporeale, S. and Pascazio, G. "Accurate numerical simulation of a high solidity Wells turbine", Renewable Energy, 33(4), pp. 735-747 (2008).

\section{Biographies}

Esmail Lakzian received his BSc degree in Mechanical Engineering from Power \& Water University of Technology (PWUT), Iran, in 2004, MSc in Mechanical Engineering (Thermo fluid) from Ferdowsi University of Mashhad, Iran, in 2006, and PhD in Energy Conversion from Ferdowsi University of Mashhad, Iran, in 2010. He has published 15 papers about wet steam flow.

Rasool Soltanmohamadi received his BSc degree in Mechanical Engineering from Azad University of Mashhad, Iran, in 2003. He is an MSc Student at Hakim Sabzevari University, Iran, and has been working on his MSc project in efficiency improvement of Wells turbine for wave energy conversion based on the first and second laws of thermodynamics under Dr. Esmail Lakzian since 2011.

Mohammad Nazeryan received his BSc degree in Mechanical Engineering from Azad University of Noor, Mazandaran, Iran, in 2013. At present, he is an MSC Student at Hakim Sabzevari University, Iran. He has also been working on his MSc project in efficiency improvement of Wells turbine for wave energy conversion based on entropy generation analysis under Dr. Esmail Lakzian since 2014. 